\title{
Nutritional Challenges and Management in DiGeorge Syndrome
}

\author{
Edwina Raj ${ }^{*}$, Sarah Zainab VJ ${ }^{2}$, Sagar Bhattad ${ }^{3}$, Chetan Gingeri ${ }^{3}$ and Mahesh DM $^{4}$ \\ ${ }^{1}$ Senior Dietitian, Department of Clinical Nutrition and Dietetics, Aster CMI Hospital, Bengaluru, Karnataka, India \\ ${ }^{2}$ Trainee Dietitian, Department of Clinical Nutrition and Dietetics, Aster CMI Hospital, Bengaluru, Karnataka, India \\ ${ }^{3}$ Pediatrician, Department of Pediatric Intensive Care Unit, Aster CMI Hospital, Bengaluru, Karnataka, India \\ ${ }^{4}$ Department of Endocrinology, Aster CMI Hospital, Bengaluru, Karnataka, India \\ *Corresponding Author: Edwina Raj, Senior Dietitian, Department of Clinical Nutrition and Dietetics, Aster CMI Hospital, Bengaluru, \\ Karnataka, India.
}

Received: October 31, 2019; Published: November 07, 2019

DOI: $10.31080 /$ ASNH.2019.03.0535

\begin{abstract}
Digeorge Syndrome also known as 22q11.2 deletion syndrome (22q11.2DS) or velocardiofacial syndrome is the most common chromosomal microdeletion disorder. It is a congenital syndrome where children usually present a clinical triad of immunodeficiency, hypoparathyroidism and congenital heart disease. We present a $1 \mathrm{yr}, 8$ month old girl child who visited to the Department of Pediatric Immunology and Rheumatology with complaints of measles and wheeze associated lower respiratory tract infection. On clinical examination she was febrile, had morbiliform rashes all over face, trunk and limbs and koplik spots in the oral cavity. The treatment given at the hospital was symptom based for diarrhoea, anaemia, hypocalcemia, oral trush, recurrent infections and seizure. Nutrition plays an important role in the growth, development and faster recovery of the patient. The purpose of effective nutrition management in DiGeorge Syndrome is to maintain the weight of the child and correct the iron and calcium levels of the child to treat anaemia and hypoparathyroidism.
\end{abstract}

Keywords: DiGeorge Syndrome; Hypoparathyroidism; Immunodeficiency; FISH Test; Koplik Spots

\section{Introduction}

DiGeorge Syndrome also known as 22q11.2 deletion syndrome (22q11.2DS) or velocardiofacial syndrome is the most common chromosomal microdeletion disorder. It occurs 1 in every 30006000 births and is equally distributed between males and females. It is a syndrome where the children usually present a clinical triad of immunodeficiency, hypoparathyroidism and congenital heart disease. This disease is also characterized by developmental delay and learning disabilities affecting $70-90 \%$ of the population.

Other characteristics of DiGeorge Syndrome includes delayed growth, breathing problems, difficulty feeding, facial abnormalities such as underdeveloped chin, low-set years, wide-set eyes or a narrow grove in the upper lip, neurological or behavioural disorders, recurrent infections, and other comorbidities.
This case report is of a 1year 8months old girl who was admitted in the PICU under the department of paediatric immunology and rheumatology with complaints of measles and wheeze associated lower respiratory tract infection. On clinical examination she was febrile, had morbiliform rashes over face, trunk and limbs, oral cavity- koplik spots. Nutrition plays an important role in the growth, development and faster recovery of the patient. The purpose of effective nutrition management in DiGeorge Syndrome is to maintain the weight of the child and correct the iron and calcium levels of the child to treat anaemia and hypoparathyroidism.

\section{Methodology}

This case study examines the nutritional intervention for the purpose of effective nutrition management of the symptoms of DiGeorge Syndrome for a 1 year 8 months old girl. 
She presented with fever, cough and rapid breathing. Since, 6-7 days which was mild in nature and progressed to wheezing associated lower respiratory tract infection from the last 2 days, rashes since 4 days, morbiliform (measles like), started in face and gradually spreading to all other parts of body, cough and cold (running nose) since 3days. On clinical examination she was febrile, morbiliform rashes over face, trunk and limbs and koplik spots in the oral cavity.

FISH study was conducted which confirmed DiGeorge Syndrome.

\section{History of the child}

- Birth history: The child was born from a Non consanguineous marriage and was a $2^{\text {nd }}$ order baby weighing $2.3 \mathrm{~kg}$.

- Developmental history: The child showed mild developmental delay and currently walks with support and can wave bye with her hand.

- Immunization history: The last immunization given to the child was at the age of 2.5 months and the child was not given measles vaccine.

\section{Past medical history}

At 2 months of age the child was admitted for 2 weeks for lower respiratory tract infection and at 2.5 months the child had recurrent LRTI, at 4 months age the child presented with wheezing and bronchiolitis and was admitted for 4 days and at 6 months the child presented with recurrent diarrhoea and also had a history of seizures associated with fever and the child was on valproate at the age of 9 months and was also diagnosed with low calcium levels.

\section{Treatment given at the hospital}

During the course in the hospital the patient had recurrent diarrhea with no signs of dehydration. She was treated with IV fluids oral zinc supplements, along with probiotics and the diarrhea resolved in 4 days.

Anemia was likely nutritional and aggravated due to the illness. The patient was given $10 \mathrm{mg} / \mathrm{kg}$ PRBC once.

Hypocalcemia was corrected by IV correction and the PTH was low hence the patient was prescribed calcium and calcitriol supplements.
Oral trush was treated with IV fluconazole and thrombophlebitis in the left hand was treated with dressing.

With the diagnosis of recurrent infections, seizures, hypocalcemia, hypoparathyroidism and low set ears a possibility of DiGeorge Syndrome was suggested by the treating team.

\section{Medication history}

Medications - she was treated with IV antibiotics and given supportive care.

\section{Nutrition care plan and intervention}

The aim was to achieve effective nutrition management in DiGeorge Syndrome for a 1 year 8 months old girl who was underweight with long standing anaemia and hypoparathyroidism.

As the child was underweight the weight of the child and the MUAC was monitored.

The weight of the child was $8.6 \mathrm{~kg}$ at the time of admission (day 1) which was in between the 3rd and 15th centile and during the follow-up (day 25) the weight increased to $9.8 \mathrm{~kg}$ which was in between the 15th to 50th centile. The MUAC of the child was $12.2 \mathrm{~cm}$ at the time of admission (day 1) which was in between -3SD and -2 SD on the growth chart and during the follow-up (day 25) the MUAC increased to $13 \mathrm{~cm}$ which was in between -2SD and -1SD indicating a significant increase in the arm circumference of the child.

The haemoglobin levels of the child was $7.6 \mathrm{~g} / \mathrm{dl}$ and calcium levels was $1.0 \mathrm{mmol} / \mathrm{L}$ at the time of admission. The parents were counselled on the iron and calcium rich foods and were also given a set of guidelines and a list of rich sources of heam iron. Some of the nutrition counselling tips that were given are

- Give short frequent meals for better absorption of the nutrients.

- Give heam sources of iron which is rich in non-vegetarian foods as it helps in better absorption of iron and take nonheam sources along with Vitamin $\mathrm{C}$ rich foods for better absorption.

- $\quad$ Always take iron rich foods with vitamin $\mathrm{C}$ for better absorption.

- Good amount of vitamin D is necessary for the absorption of calcium.

- $\quad$ As the children are picky eaters make the food colourful and attractive. 
The calcium levels of the child improved from $1 \mathrm{mmol} / \mathrm{L}$ on the day of admission (day 1) to $10.1 \mathrm{mmol} / \mathrm{L}$ on follow-up (day 54).

On the day of admission the child was in febrile condition and also had koplik spots in the oral cavity hence the intake was quite low and the calorie intake was only $364 \mathrm{kcal}, 11.9 \mathrm{~g}$ protein, $0.82 \mathrm{~g}$ fats, $1.56 \mathrm{mg}$ Iron and $20.6 \mathrm{mg}$ calcium.

After the nutrition counselling and intervention the child's intake increased to $837 \mathrm{kcal}, 33 \mathrm{~g}$ protein, $25 \mathrm{~g}$ fats, $4.37 \mathrm{mg}$ iron and $553 \mathrm{mg}$ calcium.

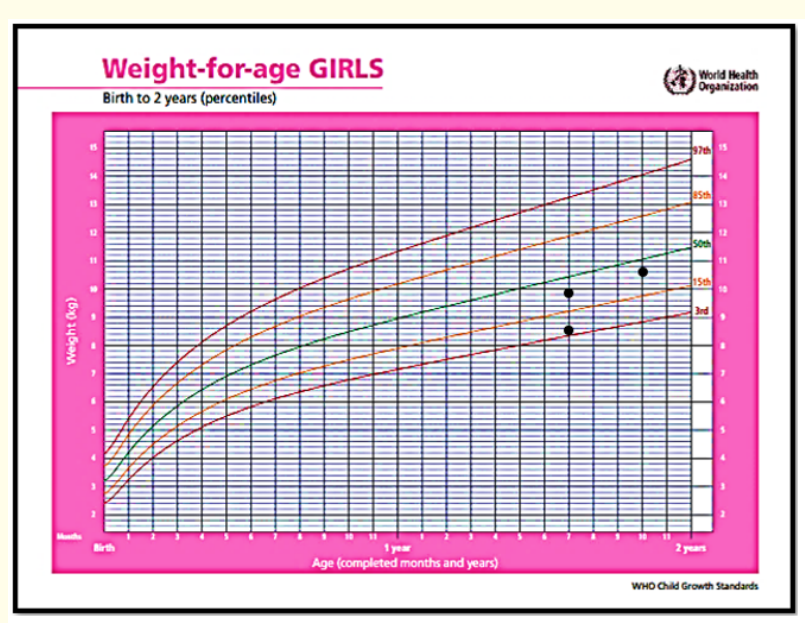

Figure 1

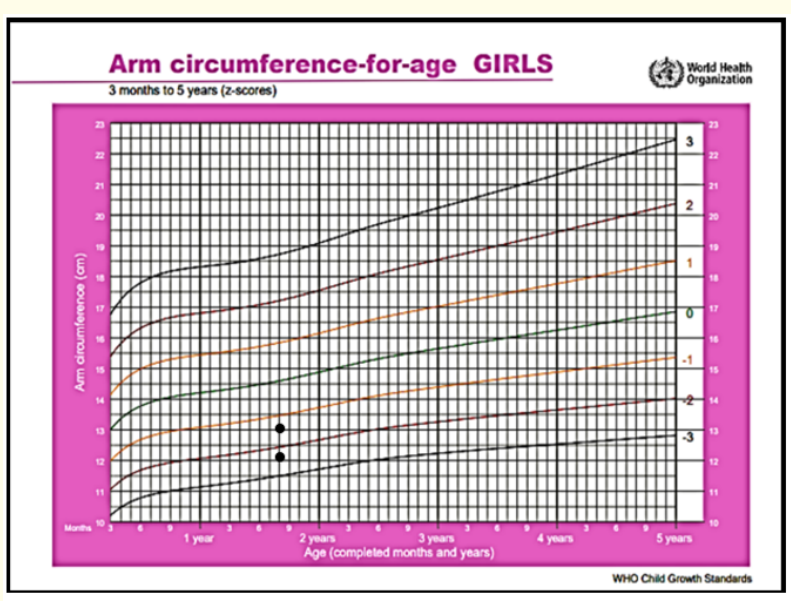

Figure 2

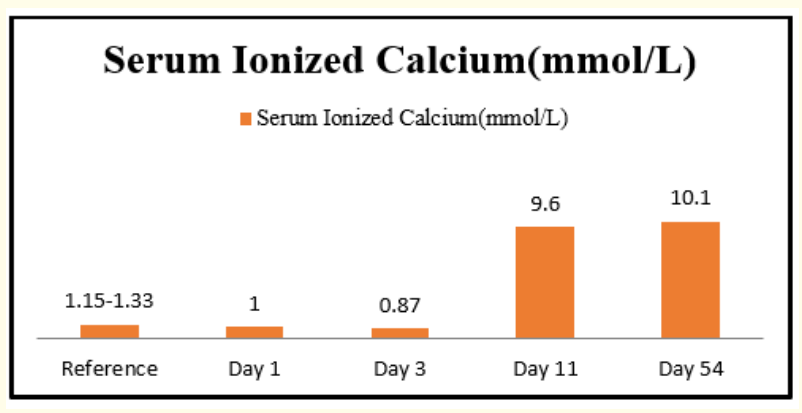

Figure 3: Serum calcium levels.

\begin{tabular}{|l|c|c|c|}
\hline DAY & Day 1 & Day 25 & Day 54 \\
\hline Weight $(\mathrm{kg})$ & 8.6 & 9.8 & 10.6 \\
\hline Height $(\mathrm{cm})$ & - & - & 78.74 \\
\hline MUAC $(\mathrm{cm})$ & 12.2 & 13 & - \\
\hline
\end{tabular}

Table 1: Weight, height and MUAC.

\begin{tabular}{|l|c|c|c|c|c|}
\hline Parameter & Reference & $\begin{array}{c}\text { Day } \\
\mathbf{1}\end{array}$ & $\begin{array}{c}\text { Day } \\
\mathbf{3}\end{array}$ & $\begin{array}{c}\text { Day } \\
\mathbf{1 1}\end{array}$ & $\begin{array}{c}\text { Day } \\
\mathbf{5 4}\end{array}$ \\
\hline $\begin{array}{l}\text { RBC count } \\
\left(10^{\wedge} 12 / \mathrm{L}\right)\end{array}$ & $4-5.2$ & 4.25 & 3.67 & - & - \\
\hline Iron $(\mu \mathrm{g} / \mathrm{dl})$ & $3.7-14.5$ & 13.3 & & - & - \\
\hline $\mathrm{Hb}(\mathrm{g} / \mathrm{dl})$ & $11-14$ & 7.6 & 6.6 & - & - \\
\hline $\begin{array}{l}\text { Serum Ionized } \\
\text { Calcium(mmol/L) }\end{array}$ & $1.15-1.33$ & 1.0 & 0.87 & 9.60 & 10.1 \\
\hline $\begin{array}{l}\text { Parathyroid } \\
\text { Hormone(pg/ml) }\end{array}$ & $14-72$ & 10.32 & 10.32 & - & - \\
\hline $\begin{array}{l}25 \text { Hydroxy Vit } \\
\text { D(ng/ml) }\end{array}$ & $\begin{array}{c}30-100 \\
\text { (sufficient) }\end{array}$ & 53.27 & - & - & - \\
\hline
\end{tabular}

Table 2: Biochemical Parameters.

\begin{tabular}{|l|c|c|c|c|c|}
\hline Nutrient & RDA & $\begin{array}{c}\text { Home } \\
\text { recall }\end{array}$ & $\begin{array}{c}\text { Hos- } \\
\text { pital } \\
\text { recall }\end{array}$ & $\begin{array}{c}\text { Dis- } \\
\text { charge } \\
\text { diet }\end{array}$ & $\begin{array}{c}\text { Follow- } \\
\text { up diet }\end{array}$ \\
\hline Energy(Kcal) & 1060 & 676.36 & 363.89 & 978.4 & 837.56 \\
\hline Protein(g) & 16 & 30.85 & 11.9 & 20.69 & 33.22 \\
\hline Fats(g) & 27 & 23.85 & 0.82 & 28.8 & 25 \\
\hline Carbohydrates(g) & - & 87.94 & 74.65 & 139.22 & 117.9 \\
\hline Calcium(mg) & 600 & 525.65 & 20.6 & 571.23 & 553.05 \\
\hline Iron (mg) & 9 & 3.29 & 1.56 & 9.08 & 4.37 \\
\hline Vitamin C(mg) & 40 & 8.04 & 0 & 199 & 8.93 \\
\hline
\end{tabular}

Table 3: Nutrient Comparison. 
Table 1 provides the amount of calories, proteins, fats, carbohydrates, calcium, iron and vitamin $\mathrm{C}$ that was consumed by the child at home, hospital when the child had measles, and on follow-up. It can be observed that the intake of the child at the hospital as quite low as the child was suffering from measles and the likely presence of koplik spots in the oral cavity can be a reason for the poor intake where as the child's intake improved on discharge and follow-up as the child's parents were counselled on increasing the protein intake of the child and also on the rich sources of protein, calcium and iron.

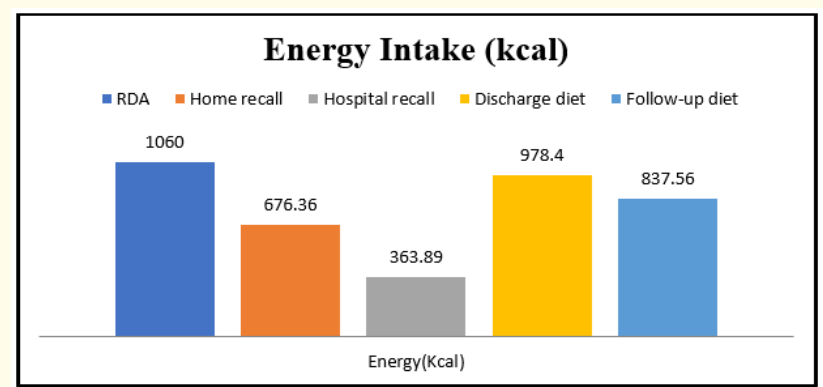

Figure 4: Calorie intake.

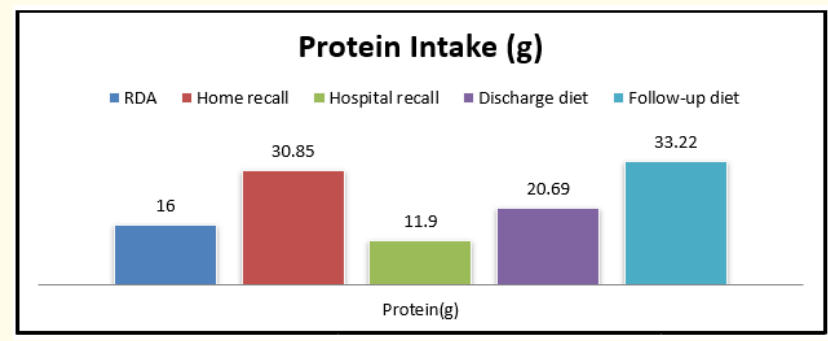

Figure 5: Protein intake.

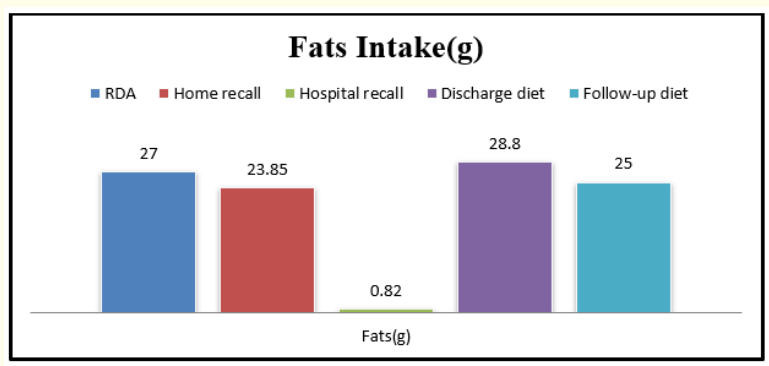

Figure 6: Fats intake.

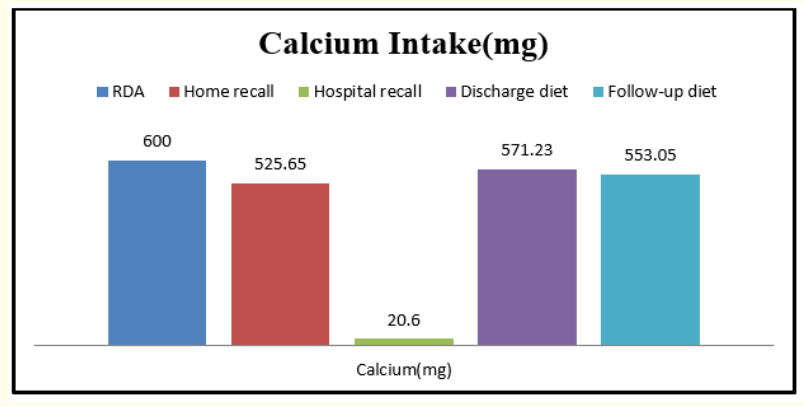

Figure 7: Calcium intake.

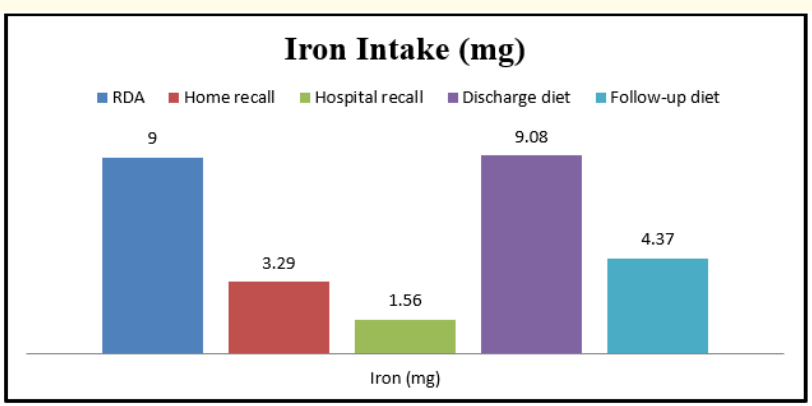

Figure 8: Iron intake.

\section{Result and Conclusion}

The case report explains a detailed nutrition management for a child with DiGeorge Syndrome where the main treatment is symptom based. In this condition the child was underweight, anaemic and had low calcium levels due to hypoparathyroidism and hence the diet mainly focused on improving the calcium and iron levels and also to maintain the weight of the child to ideal body weight (between the $15^{\text {th }}$ and $85^{\text {th }}$ percentile on the WHO weight for age growth chart). In the past 6 months there has been no readmission of the patient and the follow-up was done on an out patient basis. It can be seen that on follow-up there was gradual increase in the weight of the child from underweight to normal which was recorded in the growth chart and also an increase in the arm circumference of the child. As the child had long standing anaemia nutrition counselling was done and for hypocalcemia nutrition counselling as well as medication was given and the biochemical parameters were monitored [1-4]. 


\section{Bibliography}

1. Fomin ABF., et al. "DiGeorge Syndrome: a not so rare disease". Clinics 65.9 (2010).

2. Kraus C., et al. "DiGeorge syndrome : Relevance of psychiatric symptoms in undiagnosed adult patients". Wiener Klinische Wochenschrift 130 (2017): 283-287.

3. McDonald-McGinn., et al. "22q11.2 deletion syndrome". Nature Reviews Disease Primers 1 (2015): 15071.

4. Wang JL., et al. "DiGeorge syndrome with microdeletion of chromosome 22q11.2: report of one case". Zhonghua Minguo xiao er ke yi xиe hui za zhi 38 (1997): 385-389.

Volume 3 Issue 12 December 2019

(C) All rights are reserved by Edwina Raj., et al. 